\title{
Primary School Governance in Bangladesh: A Practical Overview of National Education Policy- 2010
}

\author{
Md. Nazmul Islam ${ }^{1}$, Al Mansor Helal ${ }^{2}$ \\ ${ }^{1}$ Ankara Yildirim Beyazit University, Ankara, Turkey \\ ${ }^{2}$ BRAC Institute of Educational Development (BIET), BRAC University, Dhaka, Bangladesh
}

\begin{abstract}
The National Education Policy- 2010 (NEP-2010), approved by the National Parliament in December, 2010, provides a framework for primary school administration. Policy gives immense power of internal supervision and monitoring to the Head Teachers (HT) of the schools, while providing little room for community people and parents in school governance by suggesting establishment of parentsteachers committee. The policy, in the process of decentralization of primary education system, empowers school management committee (SMC) to monitor school management and ensure community participation in the development activities of school. For external supervision, as a part of decentralization, every education officer is assigned certain number of schools. Annual evaluation report of teachers and HT is to be made by HT and SMC respectively. However, in reality, we find that $H T$, in many cases, is in 'all in all' role in school management; balance of power between HT and $S M C$, transparency and accountability in regard of school management is rarely found; almost no community and parents' participation in school management and development activities is found; external supervision seems insufficient and ineffective to a large extent; and annual evaluation report is often manipulated by HT. In fact, policy does not draw any clear-cut sketch which can ensure a good coordination among stakeholders and can work as a remedy to above mentioned realities. This paper suggests that education policy should have provisions which will create a balance of power between HT and SMC, and enhance check and balance and coordination among all the stakeholders in terms of school management. External supervision plays a significant role in school management. So, there should be more external supervision. This paper also aims at reflecting on effectuality of NEP2010 by going through primary data.
\end{abstract}

\section{Introduction}

A policy is a principle or rule to guide decisions and achieve rational outcomes which is intent, and is implemented as a procedure. The National Education Policy - 2010 [1], approved by the National
Parliament in December, 2010, provides a framework for fulfilling the role of the educational system in the nation's human resource development. Salient features of the policy are, a. Teaching learning process- universal education up to grade 8 , multiple delivery modes with common core curriculum and standards, literacy and non-formal education, quality improvement in tertiary education, student assessment to discourage rote learning, and vocational and technical education $b$. Administration and governance- governance and management measures. This paper will mainly shed light on administration and governance issues relating to the primary education.

Whatsoever, we find provisions of NEP-2010 relating to school governance and management is failing to fulfill the expectation in reality; decentralization process of primary education- new role of the School Management Committee (SMC), Parents Teachers Association (PTA) and system of annual evaluation report- is seeing lots of hindrances due to the absence of concrete framework for the role of SMC and PTA. This paper aims at finding out components missing out from the policy to draw a framework for the activities of SMC and PTA.

Expectation is researchers, policy makers, education officers and academics will get benefits from the findings of this paper. This paper will provide some food for thought and open up a new room for analysis of the effectuality of the existing policy and policy options. Policy makers and other stakeholders can use the findings to make a more functional SMC and PTA, thus improving primary education system.

\section{Methodology}

In this research, to identify the effectiveness of School Management Committee (SMC) and Parents Teachers Association (PTA) in regard of participation in the school development work and supervision of regular school activities, we used qualitative, quantitative data and content analysis by random sampling. Total respondents were 50 in number from 20 schools in Dhaka and its surrounding areas; 20 School Management Committee (SMC) members, 20 parents and 10 Head 
Teachers (HTs). Quantitative data were collected by closed ended questions and reviewing school documents, whereas qualitative data were collected by open ended questions. Simultaneously we went through some secondary data to have content analysis.

\section{Problem Description with Findings}

\subsection{State of Relationship between HT and SMC}

The NEP- 2010 empowers the SMC members to take part in development and other activities of the school as well as supervise and monitor HT and other teachers' work. The annual evaluation report of the HT is also supposed to be made by the SMC people as told by the policy. However, policy does not provide any legal framework- rules, regulations and jurisdiction- for SMC. As a result, most of the SMC members do not play any active role in monitoring and supervision of school activities. No social recognition or perceived benefit of SMC members, being unaware of the role and responsibility, lack of training might be responsible for not playing any proactive role. The SMC members of most the schools rarely pay any visit to the schools and hold meeting [2] [5].

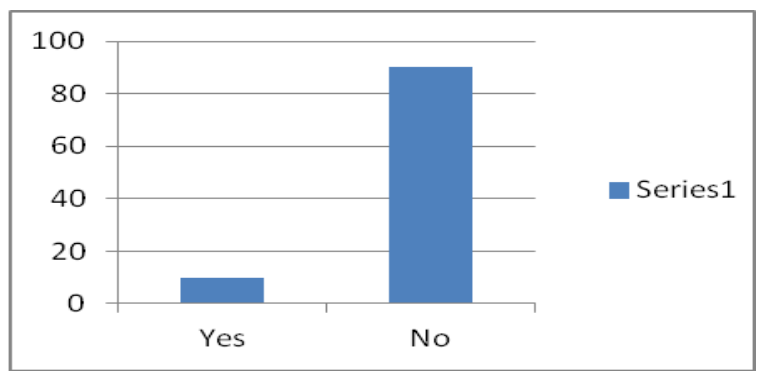

Graph 1. Percentage of SMC meeting in the last 6 months

Primary data reveals that most of the SMC members do not feel comfortable to visit school as HTs do not pay any heed to their suggestion as well as in most of the schools SMC members even chairman does not have any chair to sit in. Furthermore, even when SMC members find teachers irresponsible in regard of their duty, they cannot take any step against them. Huge room of authority for HTs and absence of legal framework of SMC's role with just mere recognition by the policy is hindering the process of coordination between HT and SMC. Furthermore, primary data shows that, in reply to an open-ended question regarding the area of responsibility of the SMC, almost $60 \%$ of the SMC members did not mention their role of supervision.
Lack of SMC meeting is another problem in the row which is making hindrances on the way of its active role play. Most of the HTs think that such meetings are of no use, while most of the SMC members reveal that HTs do not take step to hold SMC meeting.

\subsection{Transparency and Accountability}

Corruption and mis-governance are to be significant to affect the quality of education at school, which are described at three levels, at the community level by SMC, school level by the teachers, and at the level of Assistant Upazila Education Officer (AUEO) and Upazila Education Officer (UEO). Many of the issues relating to corruption and mis- governance are interrelated and cannot be accomplished without the connivance of one another. The nature of corruption and misgovernance cover the areas: irregular attendance of teachers, late arrival and early departure of teachers, dependence on Para teacher, selection and distribution of stipend money, monitoring and supervision, recording and reporting, misappropriation of development fund, private tuition [2] [5]. In addition to this, HTs do not mention the irregularities of assistant teachers in the reports. Let alone the irregularities of the HTs.

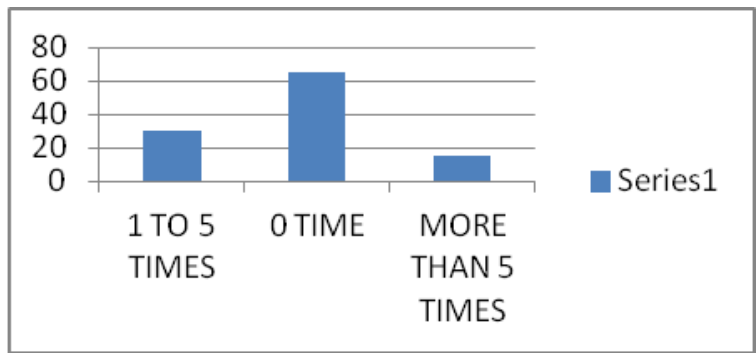

Graph 2. Percentage of the SMC members supervised in the last 6 months

Here comes the scenario of the absence of check and balance. There is no one at the school level to hold HTs accountable. Moreover, absence of effective mechanism of the triad of PTA, SMC and education officers discourages first two stakeholders of the triad to supervise; they do not have any direct meeting with education officers of higher level. If any irregularity is found how they will deal with it or go ahead with the issue to solve? There is no such provision is inserted which is making them think that my visit or supervision is of no use.

\subsection{Role of PTA}

The NEP- 2010 proposes Parents Teacher Association (PTA), a body to take part in the development activities of the school and sit in the 
regular meetings to get the updates of the school and students. However, policy does not suggest any regulatory or supervisory body to attend the meeting to see that the meetings are in place and there are some proceedings. So, there is no one to testify if meetings are really happening or not. The study "Participatory Evaluation: Causes of Primary School Dropout" conducted by RTM International on behalf of Directorate of Primary Education shows that most of the parents do not know anything about PTA and have not heard about PTA and its meetings. They do not have any knowledge about its activities. Lack of community participation and ownership of schools keep them away from every type of involvement.

Teachers do not give much importance on the parents even though this is one of the most important stakeholders of the school improvement and quality education.

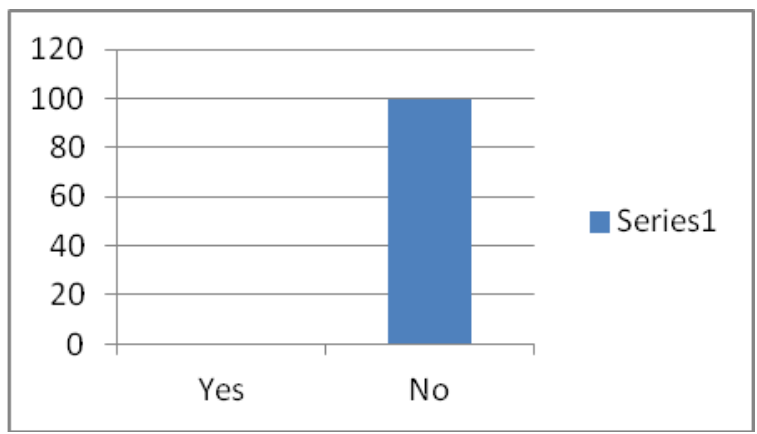

Graph 3. Percentage of PTA meeting held in the last six months

\subsection{External Supervision}

The policy suggests annual evaluation reports of assistant teachers and HTs to be made be made by Ht and SMC respectively, whereas, primary data shows, most of the SMC members do not know about this and HTs themselves make and submit the both evaluation report. Furthermore, another problem associated with supervision is, policy does not create any room for the SMC and PTA to have meeting with the external supervision team, which creates huge gap between the stakeholders directly related to the school management, which arises the question- to whom SMC or PTA would report?

Policy allocates each education officer, as a part of the decentralization process, a certain number of schools to supervise. And the study conducted by RTM International shows that one of the key reasons for poor performance of primary education system is lack of monitoring and supervision.

Moreover, we found that, $90 \%$ of the SMC and PTA members told, in the meetings, during education officers' supervision where several reports are made, no member from SMC or PTA attends, which opens up a big room for drafting fake reports.
Education officers make reports in line with the information and clues HT provides. As a result, entire process of supervision seems to be ineffective, meaningless and useless.

\section{Policy Recommendation: A Theoretical Perspective}

For policy suggestion, we have directly shed light on Fullan's "Six Secrets of Change", a model of school management and leadership in order to ensure primary school governance more functional.

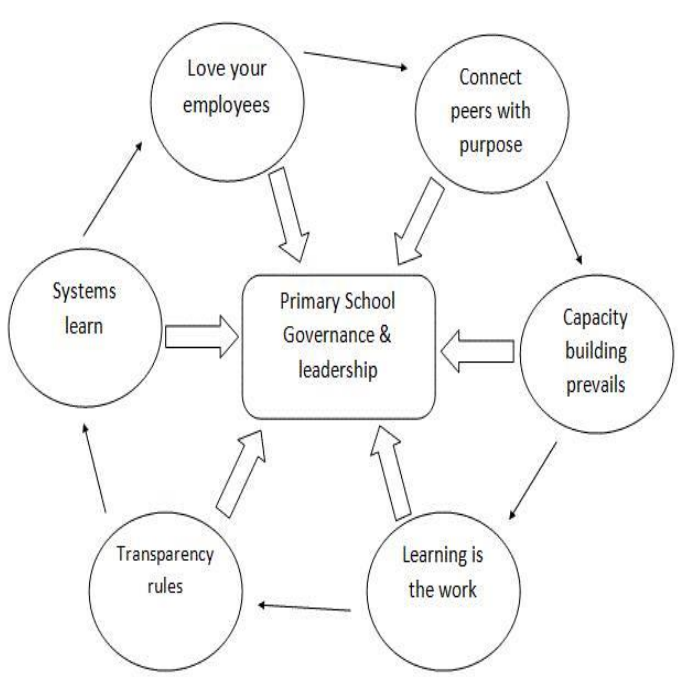

Figure 1. Fullan's Model of "Six Secrets of Change"

For the excellent primary school governance, the leadership quality of the SMC and the head teacher from primary school needs to be ensured. For having the leader's quality improvement and for the better primary school governance, the whole school improvement model of Fullan [3] can be applicable ensuring the leadership improvement with six staircases working as a cycle. As leadership is a process rather than an individual effort, participation from the end of SMC and head teacher meet the staircase from one to another, initiate the improvement in relationship and keep changing the atmosphere towards fulfilling the endeavor of governance. They can call for meeting regularly, they can share their interest, vision, plan or responsibility they want to carry on.

First insight is about affiliation between SMC and HT in both ways can set the ground building up connection and mutual trust among them and cycle goes on with shared purpose and objective for both the SMC and head teacher for the improvement of school governance. Thus, connection can provide governance the capacity to enforce them executing their vision and plan and in the same way they learn 
from each other, they learn from their ongoing task and activities, apply and maintain those accordingly. For capacity building most import step is maintaining the transparency, sharing their activities and being honest and direct about every issue. It will strengthen the bond between the HT and members of SMC.

While working together with shared vision, plan, responsibility every system learns, finds out their mistakes and finds out something better than the previous plan. It enhances the system to build up again and cycle will never end.

\section{Policy Suggestions}

\subsection{Balance of Authority between HT and SMC}

Once famous political scientist Lord Acton stated that, "Power corrupts and absolute power corrupts absolutely" [4]. We believe there should be a framework that draws the jurisdiction- role and responsibility of the SMC in order to minimize the immense authority of the HTs and create balance of authority between SMC and HT, which will hold SMC body accountable for their activities, by submitting reports and attending regular meetings, to the education officer simultaneously with the HT. Training needs to be provided for the SMC members for performing their responsibilities effectively. The responsibility of arranging the SMC meeting needs to rest on HT, SMC and education Officer. Meeting needs to be observed by the education officer directly. In terms of decision making, both HT and SMC will get similar priority. If schisms come up, education officer will interfere and make a solution. There would be a focus not only on what decisions are made and by whom, but how they are made.

Moreover, most importantly, annual report of the performance of the HTs, unlike present practice, needs to be made by the SMC people and the annual report of the whole school should be drafted in the SMC meeting in presence of both SMC and HT, so that no manipulation happens.

\subsection{Enhanced Check and Balance}

Triad of SMC, HT and education officers need to be in a solid structure to enhance check and balance in school governance. If SMC people find any teacher or HT irresponsible, unlike the present circumstances, they need to be given the rights and legal procedure to take actions by be it placing in the SMC meeting before education officer or sending a report to the higher authority. And education officers must take this report into account by making primary inquiry.
Moreover, we think SMC is the very primary stakeholder for supervision and can produce the real scenario of the school and they needs to be given more priority during education officers' visit to the school and report drafting. If SMC and HT are present in the report making process before higher authority, there is very lesser possibility of manipulation. Neither SMC nor HT can make any false statement.

There needs to have a legal status and recognition for SMC people by the law and constitution. A place for sitting and a chart of activities are to be managed in the school for the SMC body.

\subsection{Effective Use of PTA}

PTA meetings are to be in place on a regular basis to involve the parents in the governance process as well. SMC members as well as education officers need to attend this meeting. Parents need to know the progress report of their kids so that they understand their duty. Moreover, annual budget and expenditure report of the school need to be presented in the meeting so that parents feel more belonged to the school. Parents are to be given the right to raise any irregularity issue, if they find, in the meeting. Every teacher should remain open and warm to reply to the questions to be made by the parents. Such open and direct feedback and engagement of the parents in the school governance process will ensure more transparency and accountability.

\subsection{Effective External supervision}

External supervision team needs to have meeting with SMC and PTA people, so that no gap between stakeholders comes into place. There needs to be regular and frequent visit of higher education office with no prior notice of arrival. This external team is the key instrument for making coordination between PTA, HT and SMC in order to ensure a much fairer and effective governance process. This external team should have primary report of their observation which they will try to use to examine the reports to be given by SMC, PTA and HT.

This kind of external supervision and engagement with other bodies of the school will make entire school governance more transparent and make SMC and PTA body feel more valued [6].

\section{Concluding Remark}

There is linkage between school governance and educational outcome in primary education of Bangladesh. Three indicators of school governance (SGI) such as SMC, head teacher, and single shift school are instrumental to the effectiveness of the school governance [7]. At the end, we would like to 
reiterate that there needs to be a structural framework which will give room for the SMC and PTA to function. Education officers should work with HT as well as other two stakeholders to ensure a better governance system.

\section{References}

[1] Government of the People's Republic of Bangladesh. (2010). National Education Policy. Ministry of Education.

[2] RTM International Dhaka, UNICEF. (2009). Participatory Evaluation: Causes of primary school Dropout in Bangladesh. Directorate of Primary Education Bangladesh.

[3] Fullan, Michael. (2011). The Six Secrets of Change. Hoboken, NJ: Jossey-Bass.

[4] Latif, Sherezad. (2004). Improvements in the quality of primary education in Bangladesh, 1990 - 2002. UNESCO.

[5] UNICEF. (2009) Quality Primary education in Bangladesh.

[6] Social Management Framework (DRAFT) (2011). Bangladesh: Third Primary Education Development Support Program (PEDP III) Directorate of Primary Education, Ministry of Primary and Mass Education.

[7] Asadullah, M. N. (2013). School Governance and Educational Outcomes. Dhaka Bangladesh: Institute of Governance Studies, BRAC University. 